STOMACH

\title{
Cannabinoid hyperemesis: cyclical hyperemesis in association with chronic cannabis abuse
}

\author{
J H Allen, G M de Moore, R Heddle, J C Twartz
}

Gut 2004;53:1566-1570. doi: 10.1136/gut.2003.036350

See end of article for authors' affiliations

.....................

Correspondence to:

Dr J H Allen, 95 Main St

Woodside, South

Australia, 5244, PO BOX

338 Woodside, South

Australia 5244, Australia

giballen@bigpond.com

Revised version received 18 March 2004

Accepted for publication

13 April 2004
Background and aims: To explore the association between chronic cannabis abuse and a cyclical vomiting illness that presented in a series of cases in South Australia.

Methods: Nineteen patients were identified with chronic cannabis abuse and a cyclical vomiting illness. For legal and ethical reasons, all patients were counselled to cease all cannabis abuse. Follow up was provided with serial urine drug screen analysis and regular clinical consultation to chart the clinical course. Of the 19 patients, five refused consent and were lost to follow up and five were excluded on the basis of confounders. The remaining nine cases are presented here and compared with a published case of psychogenic vomiting.

Results: In all cases, including the published case, chronic cannabis abuse predated the onset of the cyclical vomiting illness. Cessation of cannabis abuse led to cessation of the cyclical vomiting illness in seven cases. Three cases, including the published case, did not abstain and continued to have recurrent episodes of vomiting. Three cases rechallenged themselves after a period of abstinence and suffered a return to illness. Two of these cases abstained again, and became and remain well. The third case did not and remains ill. A novel finding was that nine of the 10 patients, including the previously published case, displayed an abnormal washing behaviour during episodes of active illness.

Conclusions: We conclude that chronic cannabis abuse was the cause of the cyclical vomiting illness in all cases, including the previously described case of psychogenic vomiting.
S outh Australia has had more liberal laws than much of the Western World for some years now regarding the possession of small quantities of cannabis for domestic consumption. ${ }^{2}$ In the Adelaide Hills area, it has become apparent that what was previously described as "psychogenic vomiting" ${ }^{\prime 3}$ is often, in fact, cannabis related illness. This disorder, occurring in susceptible individuals, is characterised by: a history of several years of cannabis abuse, predating the onset of the vomiting illness; the hyperemesis follows a cyclical pattern every few weeks or months, often for many years, against a background of regular cannabis abuse; cessation of cannabis leads to cessation of the cyclical vomiting illness, as confirmed by a negative urine drug screen for cannabinoids; a return to regular cannabis use heralds a return of the hyperemesis many weeks or months later; and the patient will "compulsively bathe" (that is, will take multiple hot showers or baths only during the active phase of the illness).

\section{METHODS}

Nineteen patients were identified following an original clinical observation by Allen linking chronic cannabis abuse to a cyclical vomiting illness in several cases in South Australia in 2001. Patients were either referred by doctors ( 12 cases), self referred (two cases), or identified on the ward by the nursing staff (five cases) during acute admission for profuse vomiting. Of these 19 patients, five refused consent and were lost to follow up and 14 fully consented for publication and presentation. Each patient was allotted a letter of the alphabet to preserve anonymity. Patients were followed up with serial urine drug screens and regular clinical consultations to chart their clinical course.

Inpatients were observed with particular reference to autonomic changes in body temperature (measured tympanically), blood pressure, heart rate, fluid intake, skin flushing, and perspiration. However, patient anxiety, compounded by the severity of the hyperemesis, made formal autonomic testing impossible.

All reasonable efforts were made to exclude confounding causes for their cyclical vomiting given the resources at hand. As a result, five patients were excluded from the study for the following reasons:

- Polydrug use (patients O and C).

- Porphyria cutanea tarda (patient Z).

- Acute pancreatitis (patient B).

- Schizophrenia (patient T).

The remaining nine cases are presented in tables $1-4$. They were compared with a case of psychogenic vomiting described in 1996 by de Moore and colleagues. ${ }^{4}$

In their article, de Moore and colleagues ${ }^{4}$ described in detail a man ( $\mathrm{Mr} \mathrm{G})$, who had smoked marijuana as a teenager, developed a cyclical vomiting syndrome in his twenties, and was noted to have multiple showers on the ward. Marijuana was not proposed as a cause of his illness.

\section{RESULTS}

The results of the study are presented in tables $1-4$. The findings were as follows:

(a) there was a delay of several years in the onset of the vomiting illness in all cases against a background of ongoing cannabis abuse. In all cases, chronic marijuana abuse predated the cyclical vomiting syndrome;

(b) cessation of cannabis abuse led to cessation of the cyclical vomiting illness in seven patients (X, Y, A, Q, J, $\mathrm{K}$, and L);

(c) three patients (R, E, and G) did not abstain and continued to have episodes of vomiting; 
Table 1 Characteristics of the first five study subjects

\begin{tabular}{|c|c|c|c|c|c|}
\hline & $\mathrm{Mr} Y$ & Mrs X & Mr A & $\operatorname{Mr} \mathbf{Q}$ & Mr R \\
\hline Cannabis use age of onset (y) & 19 & 17 & 16 & 17 & 12 \\
\hline Cyclical vomiting (y) & 22 & 20 & 22 & 34 & 17 \\
\hline Illness duration (y) & $15 \mathrm{mths}$ & 9 & 12 & 3 & 4 \\
\hline Cannabis cessation & Well for $9 \mathrm{mths} / / 2 y$ & Well for $4 y / / 2 y$ & Well for $18 \mathrm{mths}$ & Well for $18 \mathrm{mths}$ & Did not cease \\
\hline Cannabis resumption & Vomiting at 8 weeks & Vomiting at $3 \mathrm{mths}$ & Nil & NIL & Ongoing illness \\
\hline Compulsive bathing & Multiple hot showers & Multiple hot baths & Multiple hot baths & Multiple hot showers & Multiple hot showers \\
\hline Prodromal illness & Yes (6mths) & No & Yes (1 y) & No & No \\
\hline Cannabis dose (daily dose) & Heavy (5-10 cones) & Light ( $1-5$ cones) & $\begin{array}{l}\text { Heavy (5-10 } \\
\text { cones) }\end{array}$ & Heavy (5-10 cones) & Heavy (5-10 cones) \\
\hline $\begin{array}{l}\text { Noted dose response (increased } \\
\text { cannabis use) }\end{array}$ & $\begin{array}{l}\text { Yes (increased for } \\
\text { back pain) }\end{array}$ & - & - & $\begin{array}{l}\text { Yes (increased for } \\
\text { anxiety) }\end{array}$ & - \\
\hline Hospital admissions & Multiple & Multiple & Multiple & Multiple & Multiple \\
\hline IVI fluids & Required & Required & Required & Required & Required \\
\hline Cyclical presentation (months) & $1-2$ & $2-3$ & $2-3$ & $1-2$ & $3-4$ \\
\hline Pyrexia (noted in ward notes) & Not noted & Noted & Not noted & Not noted & Noted \\
\hline Thirst & +++ & +++ & +++ & +++ & +++ \\
\hline Weight loss (kg) (during illness) & 10 & 10 & 10 & Nil & 10 \\
\hline Weight gain $(\mathrm{kg})$ (on cessation) & 10 (at 3mths) & 10 (at 3mths) & 10 (at $6 \mathrm{mths}$ ) & Nil & Nil \\
\hline Other illicit drugs used & None & None & None & None & None \\
\hline Alcohol abuse & None & None & None & None & Moderate \\
\hline Medications & PPI & PPI & PPI & PPI & PPI \\
\hline $\mathrm{PmHx}$ hyperemesis gravidarum & - & Severe & - & - & - \\
\hline Psychiatric Dx & None & None & None & None & None \\
\hline
\end{tabular}

(d) three patients (X, Y, and $\mathrm{K}$ ) rechallenged themselves after a period of abstinence and all suffered a return to illness and hospital admission. Two of these patients ( $X$ and $\mathrm{Y}$ ) subsequently abstained again from cannabis and got better and remain well. Miss $\mathrm{K}$, however, has not, and remains ill.

Collateral features included a prodromal illness in four cases (Y, A, L, and G) of episodic early morning nausea or vomiting on one or more days per week. This predated the cyclical hyperemesis by months or years. The cyclical hyperemesis occurred in all cases. The severity of illness was reflected by the frequency of hospital admissions and necessity for intravenous fluids.

A novel finding was a "compulsive bathing" or washing behaviour noted in nine of 10 patients $(\mathrm{X}, \mathrm{Y}, \mathrm{A}, \mathrm{Q}, \mathrm{R}, \mathrm{J}, \mathrm{K}, \mathrm{E}$, and G). These patients would have multiple hot showers or baths on the ward. This ritual became the patients primary preoccupation, with them often waking at night to perform it.

A number of cases had marked weight loss in the range of 5-10 kg during their illness ( $\mathrm{Y}, \mathrm{X}, \mathrm{A}, \mathrm{R}, \mathrm{K}, \mathrm{E}$, and G), with marked weight gain of approximately $5 \mathrm{~kg}$ following 3-6 months of abstinence ( $\mathrm{Y}, \mathrm{X}, \mathrm{A}, \mathrm{J}, \mathrm{K})$. Neither anorexia nervosa nor bulimia was a noted feature of the disease process. None of the patients exhibited abnormal fear of weight gain or body image distortion.

Several patients displayed a dose related response to increased cannabis use (Y, Q, J, E, G) where cannabis was employed as either an anxiolytic or analgesic. Low grade pyrexia was noted after bathing in two cases ( $X$ and $R$ ), with marked thirst and polydipsia in five cases ( $\mathrm{Y}, \mathrm{X}, \mathrm{A}, \mathrm{Q}$, and $\mathrm{R}$ ). An occasional neutrophilia was noted in six cases ( $\mathrm{Y}, \mathrm{X}, \mathrm{A}, \mathrm{R}$, $\mathrm{K}$, and $\mathrm{G}$ ). A positive cannabinoid urine drug screen was present in all cases (detected at levels $>50 \mu / \mathrm{l}$ ). Significant oesophagitis was diagnosed in five of the cases (modified

Table 2 Characteristics of the remaining four study subjects and the case of psychogenic vomiting described in 1996 by de Moore and colleagues $\left(\mathrm{Mr} \mathrm{G}^{*}\right)^{4}$

\begin{tabular}{|c|c|c|c|c|c|}
\hline & Mr J & Miss K & Mr L & MrE & Mr $\mathbf{G}^{*}$ \\
\hline Cannabis use age of onset $(y)$ & 17 & 12 & 14 & 18 & 14 \\
\hline Cyclical vomiting (y) & 44 & 14 & 17 & 32 & 20 \\
\hline Illness duration (y) & 4 & 3 & $6 \mathrm{mths}$ & 6 & 3 \\
\hline Cannabis cessation & Well for $2 y$ & Well for ly & Well for $2 y$ & Did not cease & Did not cease \\
\hline Cannabis resumption & Nil & Vomiting at $2 \mathrm{mths}$ & Nil & Ongoing illness & Ongoing illness \\
\hline Compulsive bathing & Multiple hot showers & Multiple hot baths & Absent & Multiple hot showers & Multiple hot showers \\
\hline Prodromal illness & No & No & Yes (6mths) & No & Yes \\
\hline Cannabis dose (daily dose) & Heavy (5-10 cones) & Moderate (3-4 cones) & Heavy (5-10 cones) & Heavy (5-10 cones) & Heavy (5-10 cones) \\
\hline $\begin{array}{l}\text { Noted dose response (increased } \\
\text { cannabis use) }\end{array}$ & $\begin{array}{l}\text { Yes (increased for } \\
\text { back pain) }\end{array}$ & - & - & $\begin{array}{l}\text { Yes (increased for } \\
\text { anxiety) }\end{array}$ & $\begin{array}{l}\text { Yes (increased for } \\
\text { anxiety) }\end{array}$ \\
\hline Hospital admissions & Nil & Multiple & Nil & Multiple & Multiple \\
\hline IVI fluids & $\mathrm{Nil}$ & Required & Nil & Required & Required \\
\hline Cyclical presentation (months) & $4-6$ & $2-3$ & 3 & $3-4$ & $6-12$ \\
\hline Pyrexia (noted in ward notes) & - & Not noted & - & Not noted & - \\
\hline Thirst & ++ & ++ & + & ++ & - \\
\hline Weight loss (kg) (during illness) & Nil & 10 & Nil & 10 & 7 \\
\hline Weight gain ( $\mathrm{kg})$ (on cessation) & 10 (at 6mths) & 10 (at 3mths) & Nil & - & - \\
\hline Other illicit drugs used & None & None & None & None & None \\
\hline Alcohol abuse & None & None & None & None & None \\
\hline Medications & Nil & PPI & Nil & PPI & - \\
\hline PmHx hyperemesis gravidarum & - & Severe & - & - & - \\
\hline Psychiatric Dx & None & None & None & None & ?Anxiety \\
\hline
\end{tabular}


Savary-Miller criteria: Y (grade 4), A (grade 2), R (grade 2), K (grade 2), and G). Y was the only patient to have gastric emptying studies performed acutely, displaying severely delayed gastric emptying for solids and liquids. $\mathrm{X}$ and $\mathrm{A}$ had normal studies but these were performed between episodes of illness. There was a past medical history of severe hyperemesis gravidarum (requiring hospital admission and IVI fluids) for both of the women in the study (X, K).

\section{DISCUSSION}

We found that vomiting may present in a prodromal form initially or may proceed directly to the hyperemetic stage. The phenomenon of compulsive bathing behaviour is discussed, as is a differential diagnosis, clinical management, and possible pathophysiological pathways.

\section{Prodromal illness}

Chronic cannabis abuse predated the onset of the prodromal illness. For some months or years, prior to the onset of cyclical hyperemesis, several patients (Y, A, L, and G) described the onset of early morning nausea and vomiting on one or more days a week. These patients reported nausea at the sight or smell of food and "fear of vomiting". However, unlike patients with anorexia nervosa or bulimia, they maintained normal eating patterns. Appetite was normal. Weight loss was a common feature at this stage in the presentation. Compulsive bathing was minimal or absent.

\section{Hyperemetic presentation}

This component of the illness was relatively stereotyped. The patients would start to profusely vomit, often without warning. Nausea, sweating, colicky abdominal pain, and polydipsia often accompanied these events. Patients would take multiple hot baths or showers in an attempt to quell the hyperemesis. Most attempted to cope at home unless they exhausted their hot water supply or became debilitated by severe vomiting. At this point they would present to hospital for intravenous fluid replacement. Vomiting tended to be intractable and refractory to the spectrum of antiemetic medication. The bathing behaviour was often commented on by the ward staff and noted in the case notes. Body temperature, in two cases, charted immediately following episodes of bathing, displayed low grade pyrexia. The patient's condition improved following a $24-48$ hour intravenous fluid replacement regimen. The bathing behaviour then eased and they would be discharged home. Patients represented on a cyclical basis weeks or months later, often for many years.

\section{Compulsive bathing behaviour}

The compulsion to have multiple hot showers or baths was not part of a psychosis or obsessive-compulsive disorder. This was a learned behaviour which often did not present with the first few episodes of illness (as in L) but once established rapidly became a compulsion. The symptoms of nausea, vomiting, and abdominal pain would all settle within minutes in a hot bath or shower. Symptomatic relief was temperature dependent. The hotter the water, the better the effect. As the water cooled the symptoms returned. Two patients (X, Y) even scalded themselves in an attempt to have the water as hot as possible. These patients did not exhibit delusions or hallucinations which drove this behaviour, nor did they regard the showering as irrational and did not appear to resent it. Cessation of cannabis lead to cessation of the washing behaviour.

\section{Differential diagnosis}

Cyclical vomiting syndromes fall into two distinct categories: those with a physical basis and those of unknown aetiology. Hyperemesis gravidarum and some variants of porphyria are typical toxicities, with Addison's disease ${ }^{56}$ an example of a metabolic cause.

Paediatric cyclical vomiting syndrome and psychogenic vomiting have unknown aetiologies. There has been much research into paediatric cyclical vomiting syndrome over the years. It has been associated with autonomic dysfunction, ${ }^{7}$ epilepsy, ${ }^{8}$ and behavioural problems. ${ }^{9}$ Recent research has focused on it being a variant of migraine headache ${ }^{10}$ or abdominal migraine. ${ }^{11}$ We see this disorder as a separate disease state to that exhibited by our patients with no clear associations. Although both conditions exhibit a cyclical periodicity to their vomiting, they present at different ages with no evidence of substance abuse in the paediatric group. A further consideration was whether these patients were suffering cannabis withdrawal syndrome, ${ }^{12} 13$ which occurs when cannabis is abruptly ceased, leading to a short self limiting syndrome of nausea, vomiting, insomnia, irritability, and anxiety. This was discounted on the basis that none of our patients had exhibited the desire or intent to cease cannabis. On the contrary, virtually all had increased their

Table 3 Clinical characteristics of the first five study subjects

\begin{tabular}{|c|c|c|c|c|c|}
\hline Cannabis & $\operatorname{MrY}$ & Mrs X & Mr A & $\operatorname{Mr} \mathbf{Q}$ & Mr R \\
\hline \multirow[t]{3}{*}{ Haematology $(10 \times 9 / 1)$} & $\begin{array}{l}\mathrm{Hb}: 161 \mathrm{~g} / \mathrm{l} \\
\text { WCC. } 169\end{array}$ & Hb: $156 \mathrm{~g} / \mathrm{l}$ & $\begin{array}{l}\mathrm{Hb}: 165 \mathrm{~g} / \mathrm{l} \\
W C c .152\end{array}$ & Hb: $146 \mathrm{~g} / \mathrm{l}$ & Hb: $153 \mathrm{~g} / \mathrm{l}$ \\
\hline & Neut: 15.2 & Neut: 9.7 & Neut: 13.0 & Neut: 11.9 & Neut: 10.6 \\
\hline & Plat: 277 & Plat: 261 & Plat: 237 & Plat: 239 & Plat: 225 \\
\hline Biochemistry (mmol/l) & Sod: 140, K: 4.4, Cl: 99 & $\begin{array}{l}\text { Sod: } 138, \mathrm{~K}: 4.1 \text {, } \\
\mathrm{Cl}: 98\end{array}$ & $\begin{array}{l}\text { Sod: } 148, \mathrm{~K}: 4.0 \text {, } \\
\mathrm{Cl}: 109\end{array}$ & $\begin{array}{l}\text { Sod: } 145, \mathrm{~K}: 3.5 \\
\mathrm{Cl}: 102\end{array}$ & $\begin{array}{l}\text { Sod: } 144, \mathrm{~K}: 4.0 \\
\text { Cl: } 107\end{array}$ \\
\hline Amylase & Normal & Normal & Normal & Normal & Normal \\
\hline Hep/HIV & $\mathrm{Neg}$ & $\mathrm{Neg}$ & $\mathrm{Neg}$ & $\mathrm{Neg}$ & $\mathrm{Neg}$ \\
\hline$\beta h C G$ & - & $\mathrm{Neg}$ & - & - & - \\
\hline $\mathrm{C}_{2} \mathrm{H}_{5} \mathrm{OH}$ & Nil & $\mathrm{Nil}$ & $\mathrm{Nil}$ & Nil & Nil \\
\hline Porphyria & $\mathrm{Neg}$ & Neg & Neg & Neg & Neg \\
\hline Urine drug screen $(\mu \mathrm{g} / \mathrm{l})$ & Cannabis only & Cannabis only & Cannabis only & Cannabis only & Cannabis only \\
\hline $\begin{array}{l}\text { Endoscopy (modified Savary-Miller } \\
\text { criteria) }\end{array}$ & Grade 4 erosions & Normal & Grade 2 erosions & Normal & Grade 2 erosions \\
\hline Colonoscopy & $\mathrm{Neg}$ & $\mathrm{Neg}$ & $\mathrm{Neg}$ & - & - \\
\hline Abdominal ultrasound & $\mathrm{Neg}$ & Neg & $\mathrm{Neg}$ & $\mathrm{Neg}$ & $\mathrm{Neg}$ \\
\hline Barium studies & $\mathrm{Neg}$ & $\mathrm{Neg}$ & $\mathrm{Neg}$ & Neg & - \\
\hline Gastric emptying study & Grossly delayed & Normal & Normal & - & - \\
\hline Multiple other investigations & $\mathrm{Neg}$ & Neg & Neg & Neg & Neg \\
\hline
\end{tabular}

$\mathrm{Hb}$, haemoglobin; WCC, white cell count; Neut, neutrophils; Plat, platelets; Sod, sodium; Hep/HIV, hepatitis/human immunodeficiency virus; $\beta$ hCG, beta human chorionic gonadotrophin (pregnancy test); $\mathrm{C}_{2} \mathrm{H}_{5} \mathrm{OH}$, alcohol. 
Table 4 Clinical characteristics of the remaining four study subjects and the case of psychogenic vomiting described in 1996 by de Moore and colleagues $\left(\mathrm{Mr} \mathrm{G}^{*}\right)^{4}$

\begin{tabular}{|c|c|c|c|c|c|}
\hline Cannabis & Mr J & Miss $\mathrm{K}$ & Mr L & MrE & $M r G^{*}$ \\
\hline Haematology $(10 \times 9 / 1)$ & $\begin{array}{l}\mathrm{Hb}: 143 \mathrm{~g} / \mathrm{l} \\
\text { WCC: } 7.7 \\
\text { Neut: } 3.9 \\
\text { Plat: } 234\end{array}$ & $\begin{array}{l}\mathrm{Hb}: 144 \mathrm{~g} / \mathrm{l} \\
\text { WCC: } 16.8 \\
\text { Neut: } 14.4 \text { Plat: } 280\end{array}$ & $\begin{array}{l}\mathrm{Hb}: 169 \mathrm{~g} / \mathrm{l} \\
\text { WCC: } 6.7 \\
\text { Neut: } 3.2 \\
\text { Plat: } 233\end{array}$ & $\begin{array}{l}\mathrm{Hb}: 156 \mathrm{~g} / \mathrm{l} \\
\text { WCC: } 9.0 \\
\text { Neut: } 5.1 \\
\text { Plat: } 288\end{array}$ & $\begin{array}{l}\text { WCC: raised } \\
\text { Neut: raised }\end{array}$ \\
\hline Biochemistry (mmol/l) & Sod: 140, K: 4.7, Cl: 99 & $\begin{array}{l}\text { Sod: } 143, \mathrm{~K}: 3.7 \text {, } \\
\text { Cl: } 103\end{array}$ & $\begin{array}{l}\text { Sod: } 139, \mathrm{~K}: 4.2 \text {, } \\
\text { Cl: } 98\end{array}$ & $\begin{array}{l}\text { Sod: } 143, \mathrm{~K}: 4.5, \\
\text { Cl: } 106\end{array}$ & Normal \\
\hline Amylase & Normal & Normal & Normal & Normal & - \\
\hline $\mathrm{Hep} / \mathrm{HIV}$ & $\mathrm{Neg}$ & Neg & Neg & Neg & Neg \\
\hline$\beta h C G$ & - & Neg & - & - & - \\
\hline $\mathrm{C}_{2} \mathrm{H}_{5} \mathrm{OH}$ & Nil & $\mathrm{Nil}$ & Nil & Nil & - \\
\hline Porphyria & $\mathrm{Neg}$ & Neg & $\mathrm{Neg}$ & Neg & Neg \\
\hline Urine drug screen ( $\mu \mathrm{g} / \mathrm{l})$ & Cannabis only & Cannabis only & Cannabis only & Cannabis only & Cannabis only \\
\hline $\begin{array}{l}\text { Endoscopy (modified Savary-Miller } \\
\text { criteria) }\end{array}$ & - & Grade 2 erosions & - & Normal & Mild reflux \\
\hline Colonoscopy & - & Neg & $\mathrm{Neg}$ & - & - \\
\hline Abdominal ultrasound & Neg & $\mathrm{Neg}$ & $\mathrm{Neg}$ & $\mathrm{Neg}$ & Neg \\
\hline Barium studies & $\mathrm{Neg}$ & $\mathrm{Neg}$ & $\mathrm{Neg}$ & $\mathrm{Neg}$ & - \\
\hline Gastric emptying study & - & - & - & - & - \\
\hline Multiple other investigations & Neg & Neg & Neg & $\mathrm{Neg}$ & Neg \\
\hline
\end{tabular}

$\mathrm{Hb}$, haemoglobin; WCC, white cell count; Neut, neutrophils; Plat, platelets; Sod, sodium; Hep/HIV, hepatitis/human immunodeficiency virus; $\beta$ hCG, beta human chorionic gonadotrophin (pregnancy test); $\mathrm{C}_{2} \mathrm{H}_{5} \mathrm{OH}$, alcohol.

marijuana consumption at the time of illness in an attempt to avail of its well documented antiemetic properties.

Psychogenic vomiting, first described by Hill in $1968,{ }^{3}$ as a separate entity to bulimia and anorexia nervosa, is a cyclical vomiting illness resurfacing in adult life from a tendency to vomit in childhood. Such patients commonly use illicit drugs or alcohol to control their illness. ${ }^{4}$ The uncanny resemblance of our cases to a documented case of psychogenic vomiting is remarkable. The triad of chronic cannabis, cyclical vomiting, and compulsive bathing is indicative of a new syndrome with cannabis toxicity as a cause.

\section{Clinical management}

Patients tended to fall into two categories: those that scorned the idea that cannabis was the cause of their vomiting and those that accepted the concept. The former group often refused consent to treatment and follow up. The latter group was well motivated, happy to be consented, and punctually attended appointments. All patients, for legal and ethical reasons, were counselled to cease all cannabis abuse. Benzodiazepines, used for a maximum of two weeks at the time of initial presentation, were offered to patients to avert cannabis withdrawal syndrome ${ }^{12} 13$ and psychological cravings. A member of the medical team provided an on call counselling service for any patient who had problems with abstinence. We attempted to review cases weekly for the first four weeks and then monthly for a minimum of 12 months. Psychological well being, state of health, and body weight were noted at each presentation. Each patient was required to give a consented urine drug test produced at the time of each consultation. The urine drug screen was titrated against the clinical course.

\section{Pathophysiological considerations}

Cannabis has traditionally been associated with an antiemetic action following acute ingestion. Here, however, we are presented with the paradoxical effect of hyperemesis in susceptible chronic cannabis smokers. Such a paradoxical response has only previously been demonstrated with acute toxicity to intravenous injection of crude marijuana extract. ${ }^{14}$ We suspect that susceptible individuals may develop a reaction to cannabis following several years of exposure. The reasons for this are obscure. We also have difficulty explaining why, while this disease takes years to develop, it resurfaces within weeks of cannabis resumption, even after considerable periods of abstinence.

Cannabinoids have a long half life. They are extremely lipophilic and bind to cerebral fat. ${ }^{15}$ Regular use is accumulative and this might give rise to toxicity in the sensitive patient. Cannabis is known to delay gastric emptying ${ }^{16}$ and, interestingly, one of our patients $(\mathrm{Y})$ had a severely delayed gastric emptying study at acute presentation while two others (X, A) had normal studies when investigated between bouts of illness.

Patients exhibited odd behaviour: they repeatedly bathed in hot water to abate their illness; they vomited severely and uncontrollably; they lost and gained kilos of weight in the presence and absence of cannabis, respectively; and they displayed a spectrum of autonomic symptoms from sweating, flushing, thirst, and alteration in body temperature to colicky abdominal pain.

One logical explanation for this might lie with marijuana's effect on the limbic system of the brain, particularly at the hippocampal-hypothalamic-pituitary level. ${ }^{17-19}$ Cannabis toxicity may disrupt the balanced equilibrium of satiety, thirst, digestive, and thermoregulatory systems of the hypothalamus and this disruption might settle with hot bathing or showering. A hypothalamic action is further supported by evidence that chronic cannabis use affects the secretion of pituitary hormones, suppressing growth hormone, follicle stimulating hormone, and luteinising hormone, with documented pubertal arrest. ${ }^{20}$ Cannabis cessation also results in these levels returning to normal with cessation of the disease state. ${ }^{20}{ }^{21}$ Pure hypothalamic disruption, however, does not fully explain the entire autonomic overload, suggesting other mechanisms at play. Crude cannabis is made up of over 60 different compounds. ${ }^{22}$ Any one of these in toxic concentrations may be the culprit. The mechanism of action is equally complicated. It might be due to marijuana binding to $\mathrm{CBI}$ receptor sites in the brain. ${ }^{23}$ Alternatively, anandamide, with its action on vallinoid receptor function and thermal control, may have a role here. ${ }^{23} 24$ The most recent research from Canada has shown that cannabidiol, in high concentrations, produces hyperemesis in house musk shrew models with lithium induced vomiting not acting through the $\mathrm{CBl}$ receptor. ${ }^{25}$ Clearly, further research, using models capable of emesis, is needed to detect the exact mechanism of this apparent toxic effect. 


\section{CONCLUSION}

All 10 patients described in this paper were cyclical vomiters and chronic cannabis users. All long term sufferers (nine of 10) also exhibited an abnormal bathing behaviour during the acute phase of their illness. Symptoms resolved in seven patients with cannabis abstention, confirmed by urine drug screening. Three patients rechallenged themselves by resuming marijuana and relapsed within months. Two of these three abstained again and got better, while the third did not, and remains sick. These observations suggest a causative role for chronic cannabis abuse. Simultaneous induction of cyclical hyperemesis and compulsive bathing behaviour suggests a toxic response to one or more of the active ingredients of cannabis, presumably acting, at least in part, on the limbic system of the brain. Elucidation of the responsible pathways will require further research.

The compulsion to have multiple hot showers or baths exhibited by these chronic cases is not trivial. It is clinically important to both nurse and doctor as it "flags" these patients on the ward. Their ready identification should lead to a reduction in morbidity for the patient and cost to the health service. The consequences of this discovery bear further consideration. The paradoxical effect of its action must raise concerns about the long term tolerability of marijuana. Furthermore, it would also appear clinically prudent to exclude cannabis as an underlying cause in other cyclical illnesses, such as atypical abdominal and pelvic pain. Cannabis abstention, with urine drug screen monitoring, can be titrated against a clinical course. Finally, we feel that this disorder is an important differential diagnosis for unexplained vomiting, particularly in communities tolerant of cannabis. The diagnosis can be considered or discounted with the aid of an inexpensive consented drug screen.

\section{ACKNOWLEDGEMENTS}

The authors would like to thank the following for their assistance in the production of this paper: The nursing staff of Mt Barker Hospital, especially Sr A Elliott and Sr J Hicks, Dr Matt Gaughwin, Director of Drug and Alcohol services, Royal Adelaide Hospital, and Dr David Taylor, Senior Lecturer in Neuropharmacology, Monash University.

\section{Authors' affiliations}

J H Allen, Department of Medicine, Mt Barker Hospital, Mt Barker, South Australia, Australia

G M de Moore, Department of Psychiatry, Westmead Hospital, Westmead, New South Wales, Australia

R Heddle, Department of Gastroenterology, Repatriation General Hospital, Daw Park, South Australia, Australia
J C Twartz, Department of Medicine, Ashford Hospital, Anzac Hwy, Ashford, South Australia, Australia

\section{REFERENCES}

1 South Australia. Controlled substances act, 1984.

2 South Australia. Controlled substances act-expiation of simple cannabis offences, 1987

3 Hill OW. Psychogenic vomiting. Gut 1968:9:348-52.

4 de Moore GM, Baker J, Bui T. Psychogenic vomiting complicated by marijuana abuse and spontaneous pneumomediastinum. Aust NZ J Psychiatry 1996;30:290-4.

5 Tobin MV, Morris AL. Addisons disease presenting as anorexia nervosa in a young man. Postgrad Med J 1988;64:953-5.

6 Tobin MV, Aldridge SA, Morris AL, et al. Gastrointestinal manifestations of Addisons disease. Am J Gastroenterology 1989;84:1302-5

7 Rashed H, Abell TL, Familoni BO, et al. Autonomic function in cyclical vomiting syndrome and classical migrane. Dig Dis Sci 1999:44(suppl 8):74-8S

8 Millichap JG, Lombrosco CT, Lennox WG. Cyclical vomiting as a form of epilepsy in children. Pediatrics 1955;15:705-14.

9 Forbes D, Withers B, Silburn S, et al. Psychological and social characteristics and precipitants of vomiting in children with cyclical vomiting syndrome. Dig Dis Sci 1999;44(suppl 8): 19-22S.

10 Li BU, Murray RD, Heitlinger LA, et al. Is cyclical vomiting syndrome related to migraine? J Pediatr 1999;134:567-72

11 Symon DN, Russel G. The relationship between cyclical vomiting syndrome and abdominal migraine. J Pediatr Gastroenterol Nutr 1995;21:(suppl 1)S42-3.

12 Crowley TJ, MacDonald MJ, Whitmore EA, et al. Cannabis dependence, withdrawal and reinforcing effects amongst adolescents with conduct symptoms and substance use disorders. Drug Alchol Depend 1998;50:27-37.

13 Haney M, Ward AS, Comer SD, et al. Abstinence symptoms following smoked marijuana in humans. Psychopharmacology (Berl) 1999;141:395-404.

14 Vaziri ND, Thomas R, Sterling M, et al. Toxicity with intravenous injection of crude marijuana extract. Clin Toxicol 1981;18:353-66.

15 Devane WA, Hanus L, Brever A, et al. Isolation and structure of a brain constituent that binds to the cannabinoid receptor. Science 1992;258:1946-9

16 McCallum RW, Soykan I, Sridnar KR, et al. Delta-9-tetrahydrocannabinol delays the gastric emptying of solid food in humans: a double-blind randomized study. Aliment Pharmacol Ther 1999;13:77-80.

17 Pertwee RG. Pharmacology of cannabinoid $C B 1$ and $C B 2$ receptors. Pharmacol Ther 1997;74:129-80.

18 Childers SR, Breivogel CS. Cannabis and endogenous cannabinoid systems. Drug Alcohol Depend 1998;51:173-87.

19 Herkenham M, Lynn AB, Little MD, et al. Cannabinoid receptor localization in brain. Proc Natl Acad Sci U S A 1990;87:1932-6.

20 Mueller BA, Daling JR, Weiss NS, et al. Recreational drug use and the risk of primary infertility. Epidemiology 1990;1:195-200.

21 Copeland KC, Underwood LC, Van Wyk JJ. Marijuana smoking and puberty arrest. J Pediatr 1980;96:1079-80.

22 Watson SJ, Benson JA jr, Joy JE. Marijuana and medicine: assessing the science base: a summary of the 1999 Institute of Medicine Report. Arch Gen Psychiatry 2000;57:547-52.

23 Iversen L. Cannabis and the brain. Brain 2003;126:1252-70.

24 Zygmunt PM, Petersson J, Andersson DA, et al. Vanilloid receptors on sensory nerves mediate the vasodilator actions of andandamide. Nature 1999:400:452-7.

25 Parker LA, Kwiatkowska M, Burton P, et al. Effect of cannabinoids on lithiuminduced vomiting in the Suncus murinus(house musk shrew). Psychopharmacology (Berl) 2004;171:156-61.

\section{Call for papers}

10th European Forum on Quality Improvement in Health Care

13-15 April 2005, ExCel, Docklands, London

For further information on how to submit your paper please go to:

http://www.quality.bmipg.com 